\title{
The PRISMA project: an investigation of processes controlling contaminant fluxes in the German Bight
}

\author{
Jürgen Sündermann*
}

Zentrum für Meeres- und Klimaforschung der Universität Hamburg, Bundesstr. 55, D-20146 Hamburg, Germany

\begin{abstract}
The PRISMA project is part of a hierarchy of national research projects in Germany for investigating momentum, energy and mass fluxes in the North Sea ecosystem. Its specific objectives are the identification, analysis and formulation of the physical, chemical and biological processes controlling contaminant fluxes. The necessary mesoscale and small-scale data base was acquired through multi-ship experiments in the German Bight together with numerical models. The 6 accompanying articles are devoted to an integrated presentation of the results of a drift experiment in April 1991.
\end{abstract}

KEY WORDS: North Sea · German Bight · Contaminant fluxes

\section{INTRODUCTION}

As national contributions to providing a scientific basis for North Sea protection measures, the interdisciplinary research projects ZISCH (Zirkulation und Schadstoffumsatz in der Nordsee, Circulation and contaminant transfer in the North Sea) and PRISMA (Prozesse im Schadstoffkreislauf Meer-Atmosphäre, Processes in the ocean-atmosphere contaminant cycle) were carried out during 1985-1989 and 1990-1993. The projects were headed by the Centre for Marine and Climate Research, University of Hamburg (Zentrum für Meeres- und Klimaforschung der Universität Hamburg) and funded by the German Ministry of Research and Technology (Bundesministerium für Forschung und Technologie, Bonn).

The objective of the research program was the quantification of fluxes and budgets of major contaminants in the North Sea, including heavy metals, organic contaminants and nutrients. For given anthropogenic sources, the transport paths and fates of critical substances were determined. The variability of the system due to its internal dynamics or external (anthropogenic) forcing had to be taken into account.

•E-mail: suendermann@ifm.uni-hamburg.de
The projects were complemented by other German ventures such as TUVAS (BSH 1993), the English NERC (National Environmental Research Council) North Sea project (Charnock et al. 1994) and European MAST (Marine Science and Technology) activities such as the PROFILE (Processes in Regions of Freshwater Influence) project (PROFILE 1997).

The results of ZISCH have been published in the book 'Circulation and contaminant fluxes in the North Sea' (Sündermann 1994). The PRISMA results will be published in 2 series of articles. Five papers on mass fluxes and budgets in the German Bight (suspended particulate matter, nitrogen, lead, cadmium, organochlorines) will be published in 'Marine Pollution Bulletin'. The results of a multi-disciplinary drift experiment are reported in the following 6 contributions. They will serve to improve process formulations in prognostic ecosystem models for the North Sea.

\section{RESEARCH STRATEGY OF ZISCH AND PRISMA}

For any admixture in pure water, a conservation law holds which can be described by a transport equation for the concentration of the substance. This expresses in principle that any temporal change in the concentration at a fixed location is caused by local sources and sinks or by advection and diffusion in the flow field and 
their variations. Therefore, for any assessment of the present and future contamination of the North Sea, 2 major issues have to be considered:

- the in- and outflow of contaminants due to interactions between the hydrosphere, on the one hand, and the atmosphere, biosphere and lithosphere, on the other;

- the transient 3-dimensional circulation of the water masses, including suspended particulate matter.

The internal sources and sinks of the system are characterized by sedimentological, chemical and biological processes; advection and diffusion are controlled by meteorological and oceanographic parameters. Consequently, any research project aiming at a quantification of contaminant fluxes in a marine ecosystem must address physical, chemical and biological components and their interactions.

A closer look at the whole system, its components and their interrelationships is shown in Fig. 1. It is structured horizontally according to the transport equation and vertically with respect to the transport media air, water, suspended particulate matter (SPM) and bottom sediment. Only the dominant interactions are shown.

First, we consider the purely hydrodynamic subsystem: the circulation, together with the ocean tides, drives the water circulation. These flow fields move dissolved substances, SPM and planktonic organisms which interact with each other and with the sediment. To this circulation scheme contaminants are added, resulting in their transport in air and water, both dissolved and attached to SPM. The input of pollutants originates in the anthropogenic 'external' sources via the atmosphere, rivers, the North Sea entrances and dumping within the system. Further, there are 'internal' sources and sinks such as chemical decay processes, scavenging by organisms and by SPM, as well as exchange between water and sediment. Any comprehensive program addressing circulation and contaminant fluxes in the North Sea must encompass all of the constituents shown in Fig. 1.

Another important issue is the time and space scales of contaminant transports. From an analysis of highresolution satellite images of sea surface temperatures, SPM or chlorophyll concentrations, the coherency ranges can be derived, i.e. those scales within which patterns or events are directly interrelated. For the physical compartment of the North Sea system, typical values are $5 \mathrm{~km}$ in length and $20 \mathrm{~min}$ in time. Below these intervals, causal relationships can be established between different ecosystem parameters, and processes can be studied and formulated. Above the co-

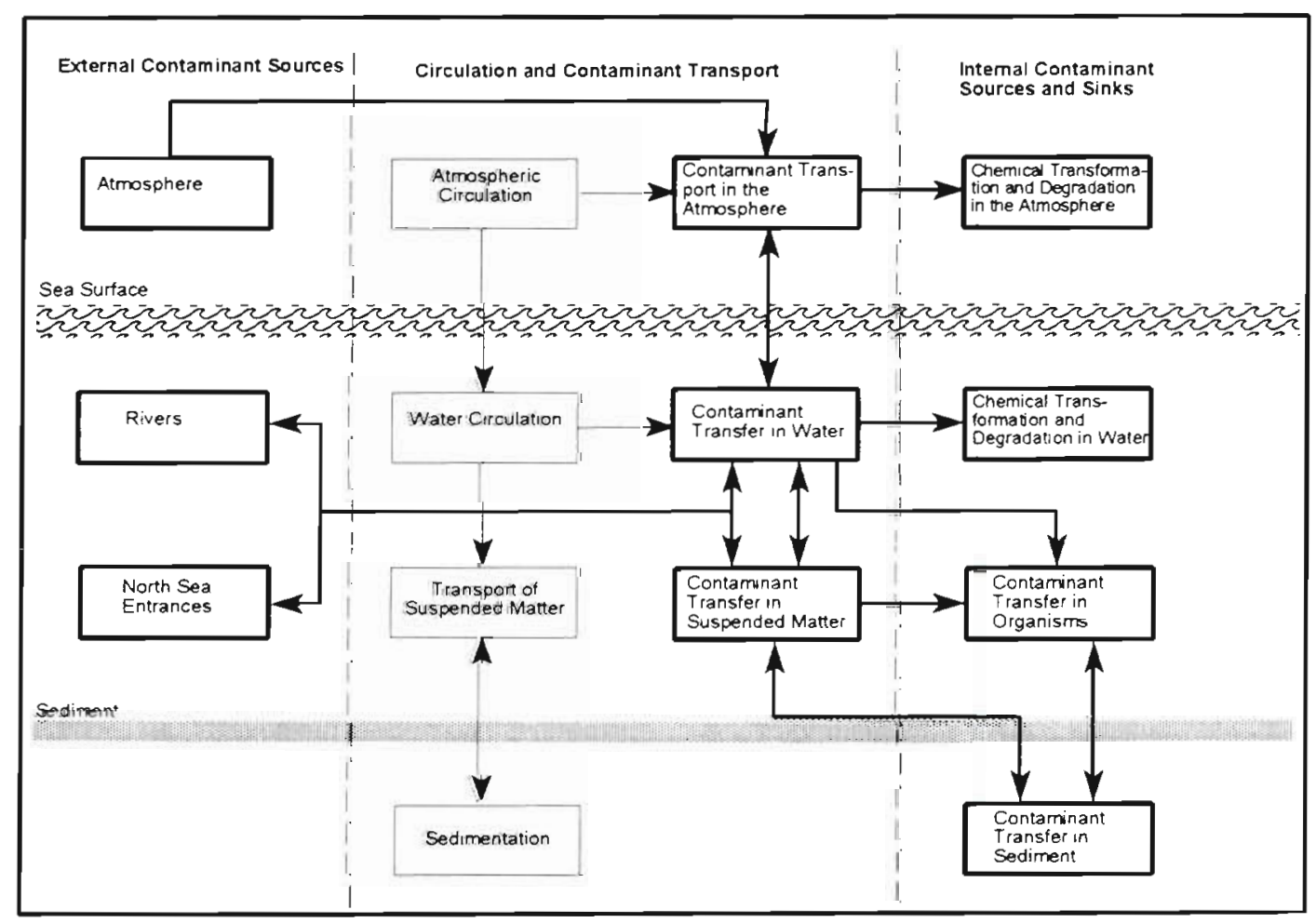

Fig. 1. Schematic diagram of circulation and contaminant fluxes in the North Sea. Thin arrows mark hydrodynamic interactions, thick ones the transport of matter (Sündermann 1994) 
herency scale, events are statistically independent and, as a rule, the deterministic treatment must be substituted for by a statistical analysis. Commonly, causal models are also used for the larger scales, but this requires an appropriate parameterisation of subscale processes.

Since the concentration of pollutants is the joint product of input (sources) and transport (advection), the same is valid for the variabilities of these parameters. This means that the high variability of the stochastic atmospheric forcing, ranging from the event scale (days) to climatological oscillations (decades), controls the ecological state of the system. There are no mean conditions in nature and consequently no mean contamination conditions.

How, then, do we obtain the means and variances, both with respect to space and time? Field experiments are expensive and scarce; they provide snap-shots within a stochastic process, i.e. they are not representative. They must be paralleled by numerical models and extrapolated from by applying these models. The bandwidth of natural fluctuations (marine weather) can be systematically determined by scenario calculations. Then, probabilities for the different North Sea states can be deduced from a statistical analysis of the long-term observed atmospheric field. The models (especially the process descriptions involved) must be extensively tested and validated against field data.

These considerations led to a 2-step research strategy:

- 2 comprehensive field experiments covering the entire North Sea, one in spring, one in winter, with measurements of all major physical, chemical and biological parameters, accompanied by model simulations (ZISCH);

- a process-oriented study in the German Bight with high spatial and temporal resolution aimed at process formulations and parameterisations for the global models (PRISMA).

The first step provided a data set above the coherency scale, serving as basic information on the ecological state of the North Sea and as a reference for model simulations. The second step provided measured and calculated data below the coherency level, serving as a basis for formulation of causal relationships. It is an integral part of the investigations.

\section{THE PRISMA DRIFT EXPERIMENT}

The German Bight is characterized by depths down to $40 \mathrm{~m}$ in the glacially formed old Elbe Valley (Elbe Rinne), extending from southeast to northwest towards the central North Sea. Connected to the bight on the land side are the (partially dredged) estuaries of the
Ems, Jade, Weser, Elbe and Eider, as well as large tidal flats and chains of islands. Together, these topographic features form a rather complex bathymetry (Fig. 2).

Strong tidal currents of up to $2.5 \mathrm{~m} \mathrm{~s}^{-1}$ form a hydrodynamic regime of high kinetic energy with a corresponding capacity for mixing and erosion. The mean tidal transport, however, is small compared to the circulation caused by the combined effects of wind, topography and density field (Backhaus 1980). The German Bight is a transition region between the freshwaters of the rivers Elbe, Weser and Ems and the salty North Sea water; it is characterized by a highly variable horizontal and vertical thermohaline stratification. Buoyancy and flow-induced turbulence form a fragile balance with changing dynamic features such as fronts, meanders and eddies (Dippner 1993, Schrum 1994, Langenberg 1996).

Three types of fronts can be distinguished (Krause et al. 1986). The first is a tidal mixing front north of the East Frisian coast. This is seasonal and is mainly observed during times of thermal stratification, when it separates the stratified from the vertically mixed water bodies (Budéus 1989). The different vertical stability on the 2 sides of the front results in different biological conditions.

The second is an upwelling front commonly found west of Helgoland in the post-glacial Elbe river valley. Northeasterly to southeasterly winds cause offshore Ekman transport which is then compensated for by an

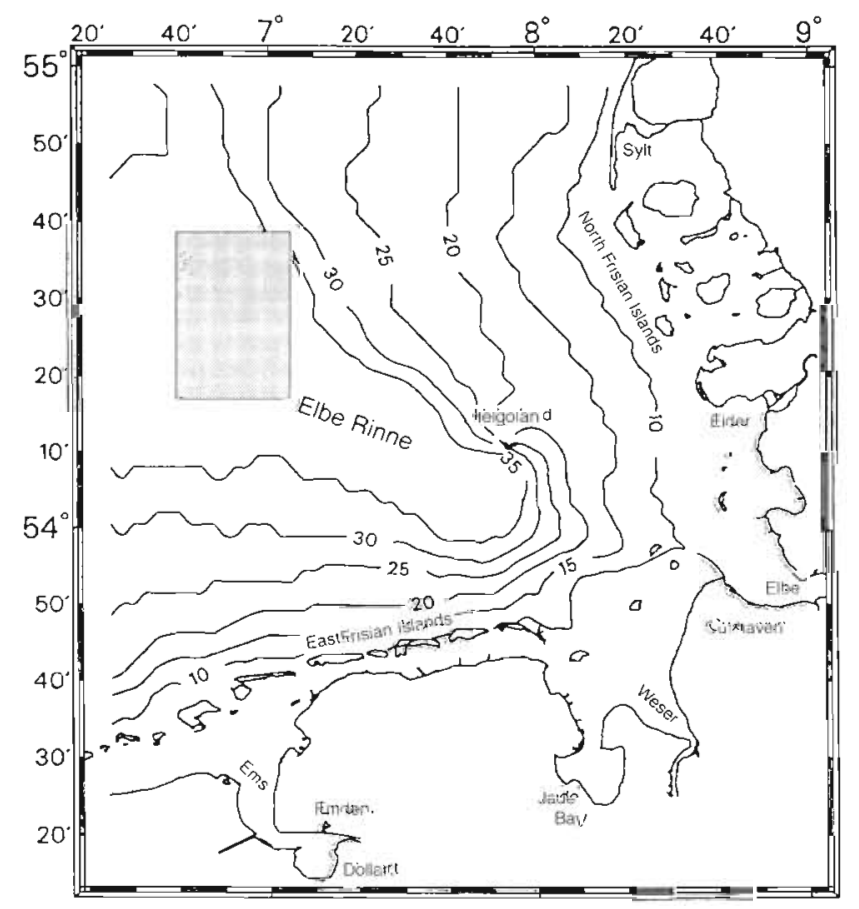

Fig. 2. Topography of the German Bight. Contour lines are in meters. The area of Drift Experiment D3 is shaded 
upwelling of southern North Sea bottom water. This process is a transient phenomenon but can be stable for up to $6 \mathrm{wk}$, depending on the prevailing winds (Dippner 1993)

The third is a permanent front caused by freshwater from land runoff overlying saline North Sea water, forming a wedge-like pattern. During normal weather conditions with steady westerly winds, a cyclonic pattern of residual currents dominates this area (Mittelstaedt et al. 1983). Consequently, the variable freshwater discharges of the rivers Elbe, Weser and Ems are mainly found in the northeastern part of the German Bight along the North Frisian coast. When northerly or easterly winds become more dominant, the average circulation in the region of the post-glacial Elbe Valley changes from cyclonic to anticyclonic with a cyclonic recirculation center (at the surface) near Helgoland (Schrum 1994). The freshwater discharge will then shift to the west with a less pronounced front.

This highly variable hydrodynamic and thermodynamic regime has a significant influence on chemical and biological transformation processes, complicating their identification, analysis and formulation. In order to simplify the description and quantification of physical conditions for process studies as much as possible, work in PRISMA concentrated on 3 drift experiments. These were carried out according to a Lagrangian sampling strategy in which an attempt was made to follow a water body marked by a buoy over a period of several days and continuously sample it.

As an example of a comprehensive, interdisciplinary analysis and synthesis for one of these field experiments, Drift Experiment D3, which took place from 23 to 29 April 1991 in the German Bight (Fig. 2), was selected. The following 6 contributions are based on this data set and concern

- the measurement strategy,

- the meteorological and hydrographic conditions at the drift stations,

- hydrographic observations and model results,

- nutrient and plankton dynamics based on the observations,

- phosphate and plankton dynamics based on a primary production model.

- the atmospheric input of lead, based on measurements and model simulations.

The contributions have a partly descriptive and partly analytical character, but they form an integral whole

\section{RESULTS OF ZISCH AND PRISMA}

Through the ZISCH experiments we acquired a quasi-synoptic but temporary picture of the contamination status of the North Sea with regard to nutrients, selected metals and organochlorine compounds in the years 1986 and 1987 The results confirmed the impression that the contamination in the coastal regions is generally greater than in the central North Sea; however, surprisingly high concentrations of some contaminants were found in areas far away from the coasts. The holistic approach, in which meteorological, hydrographical, chemical and biological parameters were measured together and complemented by meteorological and oceanographic model calculations, made it possible to synthesize the observations and interpret them in the context of the ecosystem as a whole. The data base is too small, however, to derive significant statistical relationships, and our understanding of the processes involved is not sufficient for simulation of causal principles. The models do reveal the strong controlling function of external forcing, particularly by the atmosphere. Its high degree of variability on the scale of days (events) to decades (climate) is reflected in the entire ecosystem.

The objective of PRISMA was to continue the ZISCH strategy on the smaller scale of the German Bight, placing emphasis on process studies. The strategy of following a relatively homogeneous water body in order to simplify the physical conditions for chemical and biological process studies was, for the most part, a success. It was not possible to remain in the same water body for the entire period of the drift experiment, but it was possible to sustain largely homogeneous thermodynamic conditions for periods of days at a time, permitting quantification of biological processes and turnover rates (cf. Raabe et al. 1997, this volume). Through the accompanying measurements on a regular (Eulerian) station grid in the surrounding area, hydrographically uniform water bodies and regions could be identified and the experiment could be nested into the variable structure of the German Bight. High-resolution oceanographic model simulations for the period of the experiment revealed a detailed picture of stratification, upwelling and mesoscale dynamics, with which the measured water mass distribution could be elucidated. The interdisciplinary interpretation of the data together with the results of a model for nutrient and plankton dynamics made it possible to quantify the relative roles of advection, production, decomposition and remineralization. In addition, the atmospheric nutrient and contaminant deposition could be measured and interpreted on the basis of meteorological models. The data base obtained contributed to the first formulation of a series of contaminant budgets for the German Bight (Beddig et al. 1997. Hühnerfuss et al. 1997, Puls et al. 1997a, b, Radach \& Heyer 1997, Sündermann \& Radach 1997).

ZISCH and PRISMA have clearly demonstrated that the North Sea is highly variable due to both stochastic 
meteorological forcing and the intrinsic dynamics of a nonlinear system. The time scale ranges from short events to climatological trends. Observations provide only arbitrary points in a 4D space-time continuum. This absolutely does not mean that they are worthless or unnecessary; but to be correctly interpreted, interpolations and extrapolations of measurements must be assimilated into comprehensive models of the ecosystem. The development, verification and application of such integrated models with (a certain) prognostic capability is a primary objective of North Sea research.

Scenario simulations represent the range of possible disturbances of the marine ecosystem. Monitoring data indicate which scenarios are most probable. Along these lines, research is needed mainly in order to quantify physical, chemical and biological processes and to correctly represent interactions of global- and local-scale phenomena (which involves problems of down-and upscaling).

Ultimately, the stochastic nature of the North Sea ecosystem means that an optimal quality status-however defined-cannot be achieved by any pollution management strategy. This fact strongly supports the precautionary principle for North Sea protection.

Acknowledgements. I am deeply indebted to the whole ZISCH and PRISMA group which became a very active and productive team in the course of the projects. My special thanks are due to the authors of the following contributions and to Susan Beddig, who coordinated the work and revised the articles. The Bundesministerium für Forschung und Technologie funded ZISCH unde contract nos. MFU 0545 and MFU 05765 and PRISMA under contract no. 03F 0558A1. The support of the University of Hamburg is very much appreciated

\section{LITERATURE CITED}

Backhaus JO (1980) Simulation von Bewegungsvorgängen in der Deutschen Bucht. Dtsch Hydrogr Z, Erg-H Reihe B, 15

Beddig S, Brockmann U, Dannecker W, Körner D, Pohlmann T, Puls W, Radach G, Rebers A, Rick HJ, Schatzmann M, Schlünzen KH, Schulz M (1997) Nitrogen fluxes in the German Bight. Mar Pollut Bull (in press)

BSH (1993) Transport, Umsatz und Variabilität von Schad-

This article was submitted to the editor und Nährstoffen in der Deutschen Bucht 1990-92 (TUVAS). Abschlußbericht Teil 1+2, Bundesamt für Seeschiffahrt und Hydrographie, Hamburg

Budéus G (1989) Frontal variability in the German Bight. In Ros JD (ed) Topics in marine biology. Scient Mar 53 $157-185$

Charnock H, Dyer KR, Huthnance JM, Liss PS, Simpson JH, Tett PB (eds) (1994) Understanding the North Sea system. Chapman \& Hall, London

Dippner JW (1993) A frontal-resolving model for the German Bight. Cont Shelf Res 13(1):49-66

Hühnerfuss H, Bester K, Landgraff $O$, Pohlmann T, Selke K (1997) Annual balances of hexachlorocyclohexanes, polychlorinated biphenyls, and triazines in the German Bight. Mar Pollut Bull (in press)

Krause G, Budéus G, Gerdes G, Schaumann K, Hesse K (1986) Frontal systerns in the German Bight and their physical and biological effects. In: Nihoul JCJ (ed) Marine interfaces ecohydrodynamics. Elsevier Oceanogr Ser 42. Elsevier, Amsterdam, p 119-140

Langenberg $\mathrm{H}$ (1996) Zur Dynamik haliner Fronten und ihrer Instabilitäten in der Nordsee-Untersuchungen mit einem numerischen Modell. (Dissertation.) Berichte aus dem Zentrum für Meeres- und Klimaforschung der Universität Hamburg, Reihe B: Ozeanographie, Nr. 21

Mittelstaedt E, Lange W, Brockmann C, Soetje KC (1983) Die Strömungen in der Deutschen Bucht. Publication No. 2347, Deutsches Hydrographisches Institut, Hamburg

PROFILE (1997) Processes in Regions of Freshwater Influence-PROFILE. Final report, Proudman Oceanographic Laboratory, Internal Document No. 102, Bidston Observatory, Birkenhead

Puls W, Gerwinski W, Haarich M, Schirmacher M, Schmidt D (1997a) Lead budget for the German Bight. Mar Pollut Bull (in press)

Puls W, Heinrich H, Mayer B (1997b) Suspended particulate matter budget for the German Bight. Mar Pollut Bull (in press\}

Raabe TU, Brockmann UH, Dürselen CD, Krause M, Rick HJ (1997) Nutrient and plankton dynamics during a spring drift experiment in the German Bight. Mar Ecol Prog Ser 156:275-288

Radach G, Heyer K (1997) A cadmium budget for the German Bight in the North Sea. Mar Pollut Bull (in press)

Schrum C (1994) Numerische Simulation thermodynamischer Prozesse in der Deutschen Bucht. Berichte aus dem Zentrum für Meeres- und Klimaforschung der Universität Hamburg, Reihe B: Ozeanographie, Nr. 15

Sündermann J (ed) (1994) Circulation and contaminant fluxes in the North Sea. Springer-Verlag, Berlin

Sündermann J, Radach G (1997) Fluxes and budgets of contaminants in the German Bight. Mar Pollut Bull (in press)

Manuscript received: January 2, 1997

Revised version accepted: June 2, 1997 